\title{
Change in Learning Motivation Observed through the Introduction of Design Thinking in a Mobile Application Programming Course
}

\author{
Tz-Heng Hsu ${ }^{1} * \mathbb{( D}$, Gwo-Jiun Horng ${ }^{1(\mathbb{D})}$ and Aaron Raymond See ${ }^{2}$ (D) \\ 1 Department of Computer Science and Information Engineering, Southern Taiwan University of Science and \\ Technology, Tainan 71005, Taiwan; grojium@stust.edu.tw \\ 2 Department of Electrical Engineering, Southern Taiwan University of Science and Technology, \\ Tainan 71005, Taiwan; aaronsee@stust.edu.tw \\ * Correspondence: hsuth@mail.stust.edu.tw; Tel.: +886-6-253-3131 (ext. 3226)
}

Citation: Hsu, T.-H.; Horng, G.-J.;

See, A.R. Change in Learning

Motivation Observed through the Introduction of Design Thinking in a Mobile Application Programming Course. Sustainability 2021, 13, 7492 https://doi.org/10.3390/su13137492

Academic Editor: Pedro Guilherme Rocha dos Reis

Received: 21 May 2021

Accepted: 1 July 2021

Published: 5 July 2021

Publisher's Note: MDPI stays neutral with regard to jurisdictional claims in published maps and institutional affiliations.

Copyright: (c) 2021 by the authors. Licensee MDPI, Basel, Switzerland. This article is an open access article distributed under the terms and conditions of the Creative Commons Attribution (CC BY) license (https:// creativecommons.org/licenses/by/ $4.0 /)$.

\begin{abstract}
Traditional teacher-centered teaching focused on classroom lectures has met numerous challenges in recent years, which has motivated teachers to make use of design thinking for their classes. This study made use of design thinking in an iOS programming course to find ways to improve the students' critical thinking, learning motivation and solve practical issues through mobile APP development. In the program, students were required to answer situational motivation questionnaires before and after design thinking is implemented in the course. Results showed that the values of the Cronbach's Alpha for the initial course expectation in both iterations were reliable. Subsequently, when students feel that the solutions are recognized and supported by other students and teachers in the course, there is an upward trend in the curves of their external regulation, identified regulation, and intrinsic motivation. This study successfully designed the course content and evaluation methods that have shown significant increase in the students' motivation through the incorporation of design thinking in the mobile application programming course.
\end{abstract}

Keywords: design thinking; problem-based learning; APP design

\section{Introduction}

Passive learning is a traditional method utilized in schools where students receive information from the course instructor and internalize it passively without giving feedback. As a result of a lack in practical exercises and mechanisms for solving real problems, students lose the ability of aspiration and autonomous learning [1]. In the current learning setting, students tend to acquire theoretical knowledge but do not apply the skills in their lives. As for the teachers, we need to create a classroom culture of thinking to let students immerse themselves into the lessons and acquire the mental habit of creation [2]. Many universities and colleges, such as the Hasso Plattner Institute of Design at Stanford and Olin College of Engineering, adopted design thinking methods to teach students to solve engineering problems. The design thinking training at Stanford University proposes the following key principles [3-5]: (1) Radical collaboration: Essential to have a team composed of students with various specializations and expertise to obtain opinions and inputs from different perspectives of the project. The team is then encouraged to experiment with their ideas early on, which brings in rapid prototyping. (2) Rapid prototyping: Determining what works or not early can save valuable time and resources. It also provides a hands-on learning experience. Moreover, it is important to start with the user in mind. (3) Humancentered design: It is imperative to have the user in mind before design begins. It involves human-oriented design, which is the starting point of the process. It is thinking of a design from the user's point of view, making people the source of inspiration and direction for solving design problems, and focusing on discovering users' explicit and implicit needs 
from the view of the users. (4) Creativity for everyone: Have creative impacts on the world and be an innovative thinker. Unlock creative potential in people and build creative confidence. (5) Minimize hierarchy and maximize mutual respect: Working with students as tutors, rather than solely as knowledge transfer agents. Through this method students learn more from each other rather than from the teachers' lectures.

The technological and vocational education (TVE) system is responsible for training skilled students in Taiwan. Our university, Southern Taiwan University of Science and Technology (STUST), is one of the universities entitled to promote TVE teaching that produces trained and skilled people for various industries. The authors mainly teach computer programming language courses, such as "iOS programming", "Mobile Application Practice Topics", "Web Developments", etc., and often find that students only have some principal ideas for solving real-world issues based on their past life experiences, but are unable to analyze the problems deeply and implement useful solutions. The main difficulties or problems encountered by the students in practicing computing skills courses in STUST [6] are: (1) Students are accustomed to passive learning methods, and most of them do not have the ability to find useful information, design and implement projects. (2) The way students think is not comprehensive, and they often lack skills in contemplating for the project as a whole when they solve problems. (3) When students graduate, the employers often reported that the graduates have certain technical skills, but most of them are unable to think and solve real problems independently.

Various teaching approaches and perspectives have been developed and used with design thinking in schools [7-11]. Avcu and Er gave suggestions for how a design thinking (DT) approach can be applied in the processes of teaching programming to students [12]. In [12], DT activities were applied to 25 gifted students at the Science and Art Center (BILSEM) through the summer term. After participating in DT process, students stated that they enjoyed DT activities. Tsai and Wang inspect the relationship between young students' design thinking personality and their computer programming self-efficacy [13]. To evaluate students' design thinking dispositions, the authors established the Design Thinking Disposition Scale (DTDS) with 350 junior high school students who had computer programming experience in a STEAM course. The students' learning experience was shown to benefit the design thinking disposition [13]. Rajashekharaiah et al. developed a modified standard "Design Thinking Framework" through structured enquiry assessment [14]. It shows that the students are able to use object-oriented concepts efficiently to solve problems, design solutions and perform better in the semester examinations. Subsequently, teaching methods are closely related to teaching design and teaching effectiveness, affecting teaching effectiveness and learning quality. By mastering the teaching context and understanding the influence of teaching design and teaching methods, teachers can choose and organize relevant teaching methods and use them to achieve the desired teaching results. Design thinking is a user-oriented problem-solving methodology that seeks innovative solutions for resolving various issues and creates more possibilities by starting from user needs $[15,16]$. Design thinking makes decisions based on what users really want, not just based on historical data analysis or risky decisions made based on intuition [17,18].

The challenge for professors is "How can teachers cultivate students who can think and solve real problems?" In this study, we made use of the iOS Programming course to cultivate the interest of students to design and implement mobile applications through design thinking teaching strategies and problem-based learning, using the methods of "empathy", "demand definition", "creative brainstorming", "prototyping", and "real-world testing", putting forward real problems and training the students' practical skills through thinking, discussion and learning methods.

\section{Research Objectives}

The study made use of the iOS Programming course with the objective of developing the students' ability to think, analyze and solve practical problems. The course content is designed through design thinking and problem-based learning methods, with practical 
problems as the core. It is important to encourage the students to discuss, cultivate students' ability to learn, think and solve problems actively. Thus, in this study, we will explore the behaviors of TVE students in a mobile application programming class, and explore the changes in their learning motivations after participating in the design thinking teaching method. The study objective is to use design thinking methods to guide students to devote themselves in the learning activities and improve their learning motivation.

\section{Methodology}

\subsection{Research Methods and Tools}

The research architecture is shown in Figure 1. Before carrying out the design thinking methods, the students were first subjected to answer two questionnaires that included a reliability analysis of the initial course expectation and a pre-test using a situational motivation questionnaire. Causality orientation theory considers the role of individual differences in motivational orientations, which is being defined based on self-determination theory $[19,20]$. According to self-determination theory (SDT), people can be intrinsically motivated and/or extrinsically motivated $[19,21]$. The self-determination theory is a critical theoretical perspective for examining and comprehending students' learning motivation. Based on this theory, this study uses the revised Situational Motivation Scale (SIMS) compiled by Guay et al. [22] to collect data and examine students' learning motivation after teaching with design thinking methods.

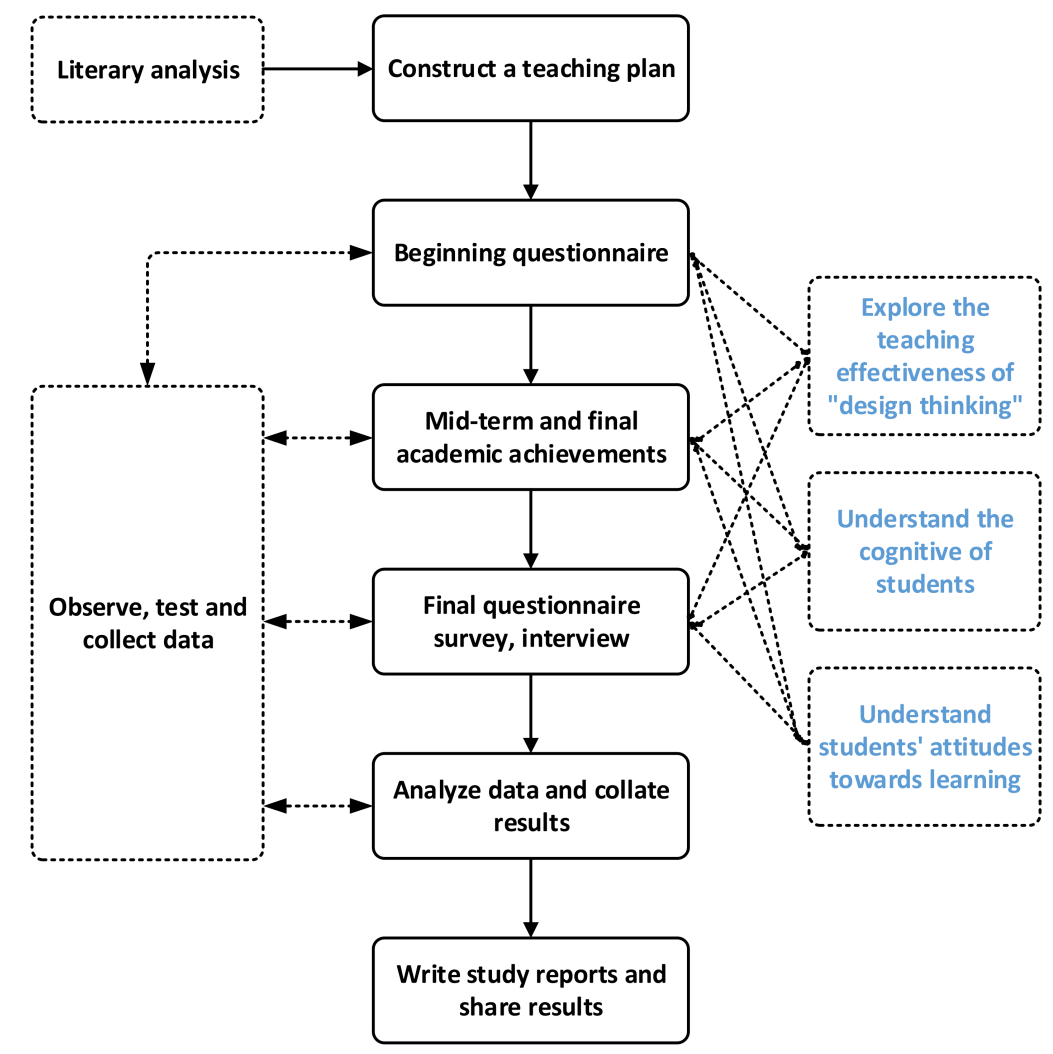

Figure 1. The research architecture.

Situational motivation discusses the motivation experience when people are involved in an activity [23]. The Situational Motivation Scale (SIMS) is measured two weeks before and after the design thinking activities. SIMS is a 16-question scale used to assess the learning motivation of students after the design thinking activities. Intrinsic learning motivation represents the highest degree of self-determined motivation and the individuals' interests and enjoyment of learning. Moreover, identified regulation represents understanding and recognition of the importance of curriculum activities, and external regulation represents 
passive cooperation due to curriculum regulations or peer pressure [24]. The SIMS was scored according to the 7-point Likert scale, with 1 as totally disagree and 7 as completely agree. The SIMS is divided into four dimensions, including 4 questions on Intrinsic motivation (IM), 4 questions on Identified regulation (IR), 4 questions on External regulation (ER) and 4 questions on Amotivation (AM). After the end of the semester, the evaluation of learning effectiveness will be carried out, including project work and end-of-term learning questionnaires, to understand students' learning status, learning achievements and knowledge growth. This study will use the above tools to collect the required information, continuously improve the quality of teaching, using it as a basis for analyzing students' learning growth process and learning effectiveness.

\subsection{Course Content and Planning}

This study focuses on the learning outcomes of design thinking and iOS programming, and guides students from the Department of Computer Science and Information Engineering (CSIE) to design mobile applications to solve real-world problems, and to explore issues related to computer programming language learning.

The subjects of this study are senior students in the STUST CSIE. They all had basic programming skills but had not previously studied iOS programming. There are two classes in different semesters-namely, (1) the first semester of the 2019 academic year where there were 19 students in total, 17 males and 2 females. (2) The first semester of the 2020 academic year: There were 41 students in total, including 38 males and 3 females. The course's curriculum planning is based on the 18-week iOS programming course. There are three iOS programming lessons per week, each with $50 \mathrm{~min}$, with a total of 54 lessons. Table 1 shows the contents and curriculum planning. One week before the introduction of design thinking teaching, students took the SIMS pre-test. After the pre-test, a two-week design thinking teaching intervention lesson would be conducted, and a post-test of the SIMS would be conducted after the teaching intervention was completed.

Table 1. Content and planning of teaching materials.

\begin{tabular}{|c|c|c|}
\hline Week & Lesson Topic & Content Description \\
\hline 1 & Logistics, iOS Overview and MVC & iOS object-oriented programming and MVC development method \\
\hline 2 & Xcode and Interface Builder & Introduction to Xcode Development Tool \\
\hline 3 & Swift programming language & Introduction to Swift programming language \\
\hline 4 & Auto Layout & Use Auto Layout and stacked view to build adaptive User Interface \\
\hline 5 & App prototype design & App prototype design and pre-planning \\
\hline 6 & Tabular App Basic Design & Design and implement basic table style App \\
\hline 7 & Use Prototype Cell to customize the table view & Customize the table view cell to enhance the presentation of table data \\
\hline 8 & Table view interaction & Handle table column deletion and sliding actions \\
\hline 9 & Mid-term programming practice exam & Test students' practical ability \\
\hline 10 & APP design thinking & App idea brainstorming, Persona, and User Story design. \\
\hline 11 & APP prototyping & $\begin{array}{l}\text { The team self-assessed the importance of each function, compares each } \\
\text { process, and develops a prototype. }\end{array}$ \\
\hline 12 & User confirmation and detail interface design & $\begin{array}{l}\text { The user confirms, determines the design, and draws the detail } \\
\text { user interface. }\end{array}$ \\
\hline 13 & Map application & How to tag data on the map \\
\hline 14 & Basic animation, visual effects & Create animation and visual effects \\
\hline 15 & Camera & Start the phone camera, take and save pictures. \\
\hline 16 & Core Data & Save data to database \\
\hline 17 & Thinking and feedback & Discuss the problems of project development \\
\hline 18 & Final project report & Evaluations of the final project reports. \\
\hline
\end{tabular}




\subsection{Study Field and Equipment}

In this study, each student was assigned a Mac computer. It includes the software Xcode program designed for iOS programming. After teaching the design thinking methods, students would make use of Marvel software, a prototype design tool that accelerates the iterative design process for them to implement the prototype's interactive design in their mobile application. In the prototyping stage, designers can configure the interactive behaviors between interfaces by drawing graphics; when the prototype design is completed, it can be directly released to the testers, accelerating the process for the design team to make more efficient mobile application prototypes. Therefore, the two main software and hardware equipment mentioned above are used to support the mobile application design.

\subsection{Teaching Process}

Dam and Siang [25] described the five-stage design thinking model proposed by the Hasso-Plattner Institute of Design at Stanford (d.school). According the five-stage design thinking model in $[4,5,25]$, the process of design thinking used in the iOS programming course is described as follows: (1) Empathy: human-centered design aims to find the real problems and demands of users through gathering information from a user's perspective. (2) Demand definition: after the information collected in the "empathy" step, using methods such as "architecture", "delete", "dig deep", "combination", etc., the problem can be redefined more deeply. (3) Ideate: come up with a variety of solutions to solve the problems found in the "demand definition" step, stimulate creative ideas in the brain, and find a truly suitable solution. (4) Prototype: a specific presentation method is used as a tool for communication within the team and users to make thinking clearer. In addition, it can be presented by simple sketches, and constantly modified to achieve a more perfect outcome. The output results of this stage will be used for testing. (5) Use the prototype produced in the previous stage to communicate with the users through situational simulations. The users can test whether the prototype is applicable or not. By observing the user's response, redefine the demand and propose a new solution.

The teaching process is shown in Figure 2. This study uses the following methods to improve the teaching effectiveness and students' technical ability:

- Foundation: To lay a solid foundation, students construct preliminary knowledge through classroom teaching and divide them into different project groups.

- Brainstorming: The teacher designs several real problems, and then each group writes out the problem that they want to solve, discussing it with the team to generate possible solutions.

- User interview: Using Persona and writing user story methods, students try to find out the needs of the users.

- Prototype design: The students propose the most desired functions for the solution. The team will self-assess the importance of each function and fill in the function list form. Students put forward each group's plan and draw a high-level flow chart based on each function that eventually forms the prototype wireframe.

- User confirmation: Invite users to discuss whether the process and interface design give good user experience. Decide on the final design and draw the detailed user interface.

- System implementation: Students perform the system design, illustrate the workflow charts and implement the mobile applications.

- Thinking and feedback: Back to the classroom, the students discuss the knowledge that is lacking in the process of implementation, and then are complemented by the teacher.

Due to the course's time constraints, the teachers must devote the majority of its time to teaching students the Swift programming language and iOS App interface design. In the traditional design thinking process, it usually takes $3-5$ days to complete a whole design sprint activity. However, such a long time is unattainable for this course. Regarding design 
thinking activities in the course, the time must be shortened while keeping the advantages of design thinking activities. Therefore, we developed the rapid design thinking conception form in order to let students quickly conceive and design apps in the classroom. The proposed rapid design thinking conception form combines Persona, Use Case, Feature List and App Prototype, so that students can describe the design ideas quickly and clearly in one page, which is helpful for the overall conception. Figure 3 shows the proposed rapid design thinking conception form. Subsequently, this study hired an external expert professor Lee [26] who has many years of experience organizing design thinking workshops to lead the students in conducting design thinking processes in the 2019 academic year. He encouraged students to think about problems deeply, conduct user interviews, propose solutions, hands-on design and implementation, and make conceptual prototypes. Figure 4 illustrates the organized design thinking workshops to help students create ideas for solving real-world problems in the 2019 academic year. According to the results of the students' exercises, we believe that the workshop and the rapid design thinking conception form are successful in stimulating students to think comprehensively. All students can immediately apply the items on the form in a short time to complete the description of thoughts, and finish related design activities, such as Persona, Use Case, Feature List and App Prototype.

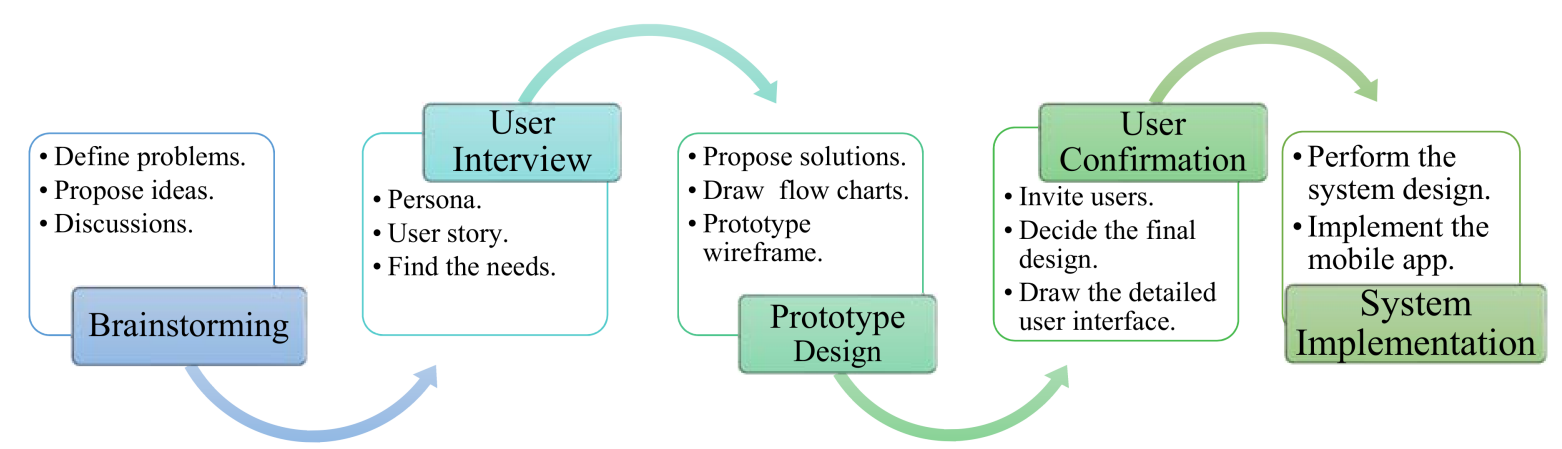

Figure 2. The teaching process that includes brainstorming, user interview, prototyping, implementation, user confirmation, and system implementation.

Goal:

Name:

Persona

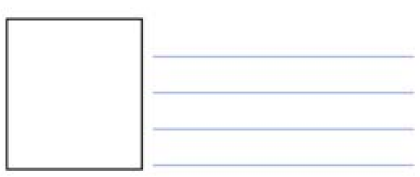

Use Cases

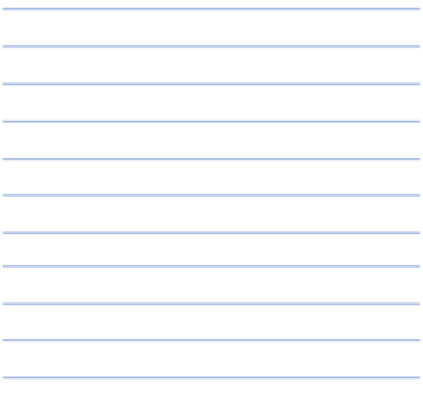

(2)

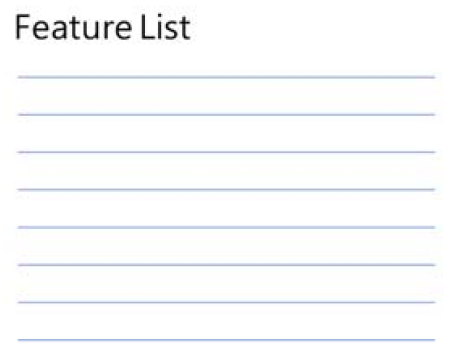

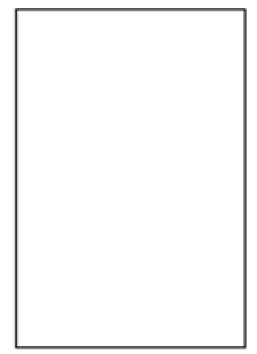

(2)

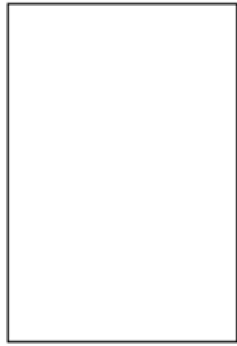

(3)

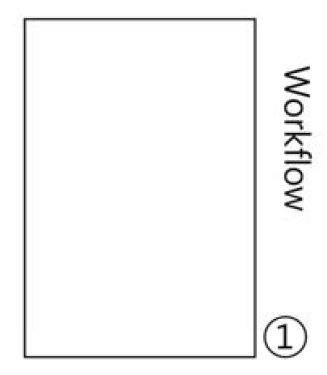

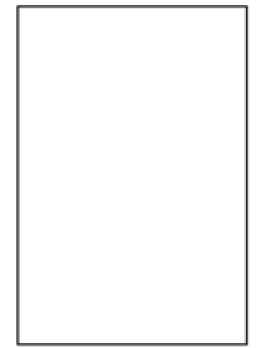

(4)

Figure 3. The proposed rapid design thinking conception form for quick prototyping. 


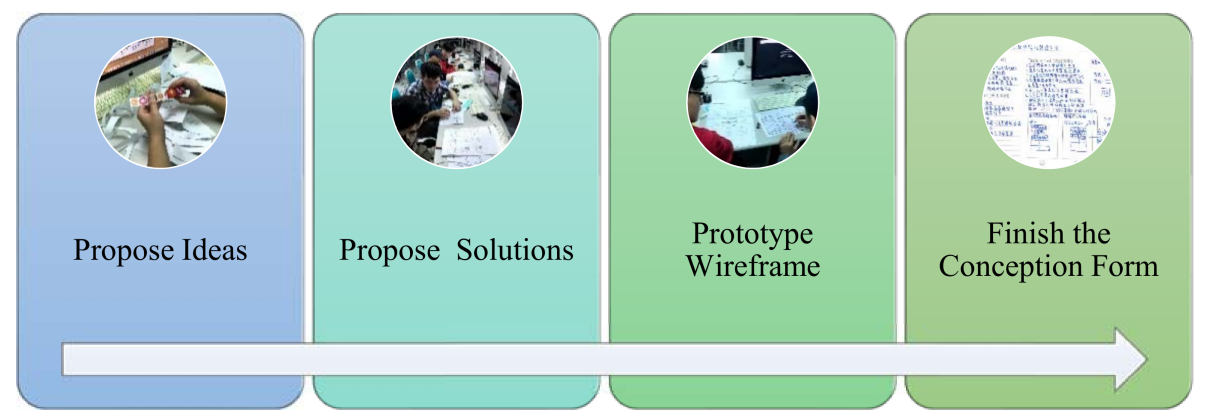

Figure 4. The organized design thinking workshops to help students create ideas for solving realworld problems in the 2019 academic year.

\section{Results}

\subsection{Reliability Analysis of the Initial Course Expectation Questionnaire}

Reliability measures the consistency and relative lack of error. The Cronbach's alpha $(\alpha)$ and composite reliability $(\rho)$ are the reliability coefficients used to evaluate the internal consistency [27].

Table 2 depicts the initial course expectation questionnaire. GNU PSPP 1.4 [28] statistical software was used to perform the statistical tests and analyses described below. With the participation of the students in the iOS programming course in the two semesters that the program is conducted. The Item-Total Statistics results of the initial course expectation questionnaire are shown in Table 3. It demonstrated the value of Cronbach's Alpha for the initial course expectation questionnaire in the first year as $0.72>0.7$ and the second year as $0.89>0.7$, both of which indicate reliability.

Table 2. The initial course expectation questionnaire.

\begin{tabular}{l} 
Questionnaire \\
\hline Q1. I am very interested in learning iOS courses. \\
Q2. I think learning iOS courses is helpful to my future employment. \\
Q3. I think the learning materials selected by the teachers meet the core objectives of the curriculum. \\
Q4. I think the course syllabus can clearly convey the content of the course. \\
Q5. I am very interested in the iOS course integrated with design thinking methods. \\
Q6. I am very interested in designing my own iOS APP project at the end of the semester. \\
\hline
\end{tabular}

Table 3. The Item-Total Statistics results of the initial course expectation questionnaire in the course: (a) The first semester of the 2019 academic year; (b) The first semester of the 2020 academic year.

\begin{tabular}{lcccc}
\hline & \multicolumn{2}{c}{$(\mathbf{a})$} & \\
\hline & $\begin{array}{c}\text { Scale Mean } \\
\text { If Item Deleted }\end{array}$ & $\begin{array}{c}\text { Scale Variance } \\
\text { If Item Deleted }\end{array}$ & $\begin{array}{c}\text { Corrected Item-Total } \\
\text { Correlation }\end{array}$ & $\begin{array}{c}\text { Cronbach's Alpha If } \\
\text { Item Deleted }\end{array}$ \\
\hline Q1 & 20.55 & 5.97 & 0.5 & 0.66 \\
Q2 & 20.36 & 6.53 & 0.54 & 0.67 \\
Q3 & 20.36 & 6.62 & 0.5 & 0.67 \\
Q4 & 20.32 & 6.99 & 0.44 & 0.69 \\
Q5 & 20.55 & 5.69 & 0.41 & 0.7 \\
Q6 & 20.82 & 4.54 & 0.53 & 0.67 \\
\hline & & & & Cronbach's Alpha If \\
Item Deleted \\
\hline Q1 & Scale Mean & Scale Variance & Corrected Item-Total \\
Q2 & If Item Deleted & Correlation & 0.82 \\
Q3 & 18.95 & 7.5 & 0.74 & 0.82 \\
Q4 & 18.7 & 7.68 & 0.73 & 0.82 \\
Q5 & 18.78 & 7.94 & 0.74 & 0.86 \\
Q6 & 18.92 & 8.56 & 0.53 & 0.82 \\
\hline
\end{tabular}


In Table 4, it shows that students are interested in taking iOS courses, but some students are less interested in designing final projects by themselves at the end of the semester (Q6). The possible reason is that the final design project requires writing reports, programming, and finishing APP applications, which puts a heavy burden on the students academic work, so students do not like to design and implement APP applications but will regard the final topic as a burden.

Table 4. The Descriptive Statistics results of the initial course expectation questionnaire in the course: (a) The first semester of the 2019 academic year; (b) The first semester of the 2020 academic year.

(a)

\begin{tabular}{|c|c|c|c|}
\hline & Mean & Std Dev & Variance \\
\hline Q1 & 4.05 & 0.72 & 0.52 \\
\hline Q2 & 4.23 & 0.53 & 0.28 \\
\hline Q3 & 4.23 & 0.53 & 0.28 \\
\hline Q4 & 4.27 & 0.46 & 0.21 \\
\hline Q5 & 4.05 & 0.9 & 0.81 \\
\hline Q6 & 3.77 & 1.11 & 1.23 \\
\hline \multicolumn{4}{|c|}{ (b) } \\
\hline & Mean & Std Dev & Variance \\
\hline Q1 & 3.76 & 0.76 & 0.58 \\
\hline Q2 & 3.84 & 0.73 & 0.53 \\
\hline Q3 & 4 & 0.67 & 0.44 \\
\hline Q4 & 3.92 & 0.68 & 0.47 \\
\hline Q5 & 3.78 & 0.71 & 0.51 \\
\hline Q6 & 3.41 & 0.8 & 0.64 \\
\hline
\end{tabular}

\subsection{Analysis of Changes in Learning Motivation of Design Thinking Teaching Intervention}

With the participation of the students in the design thinking teaching methods in the first semester of the 2019 academic year and the first semester of the 2020 academic year, the results of the differences in learning motivation changed after participating in the design thinking lessons as shown in Table 5 and Figure 5.

Table 5. The results of the differences in learning motivation changed after participating in the design thinking lessons: (a) The first semester of the 2019 academic year; (b) The first semester of the 2020 academic year.

(a)

\begin{tabular}{lcc}
\hline & $\mathbf{2 0 1 9 - 1 0 - 1 4}$ & $\mathbf{2 0 1 9 - 1 2 - 2 6}$ \\
\hline Intrinsic motivation (IM) & 5.11 & 5.82 \\
Identified regulation (IR) & 5.41 & -5.93 \\
External regulation (ER) & 4.97 & 5.16 \\
Amotivation (AM) & 3.53 & 3.26 \\
\hline & $\mathbf{( b )}$ & $\mathbf{2 0 2 1 - 1 - 2 1}$ \\
\hline Intrinsic motivation (IM) & $\mathbf{2 0 2 0 - 1 1 - 0 5}$ & 5.38 \\
Identified regulation (IR) & 4.81 & 5.55 \\
External regulation (ER) & 5.18 & 5.14 \\
Amotivation (AM) & 4.76 & 3.88 \\
\hline
\end{tabular}



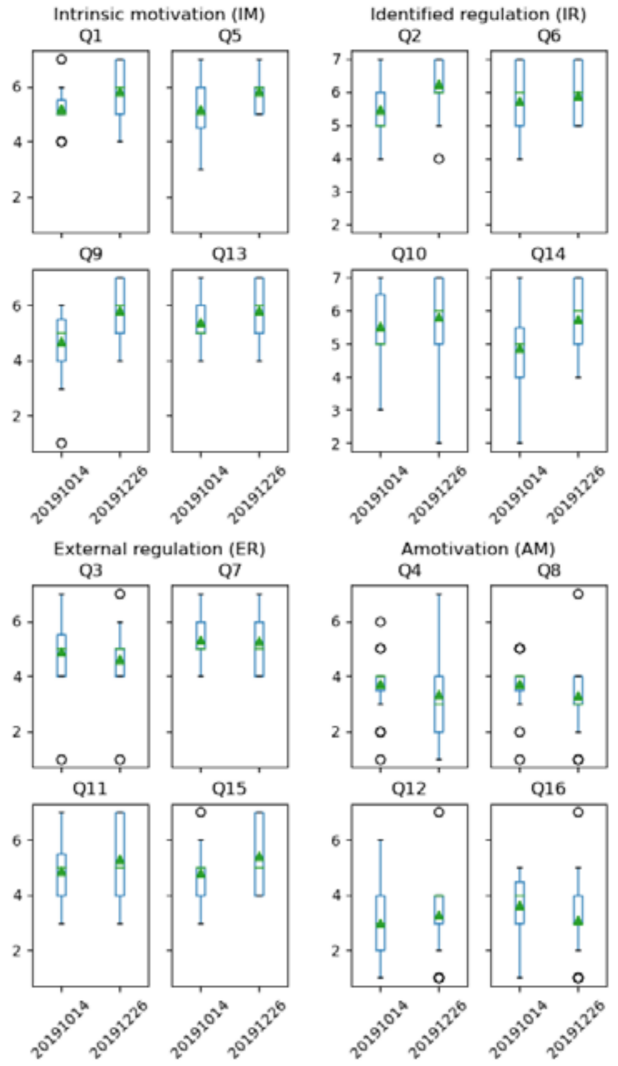

Amotivation (AM)
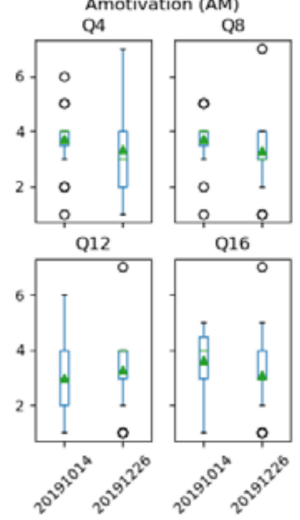

(a)
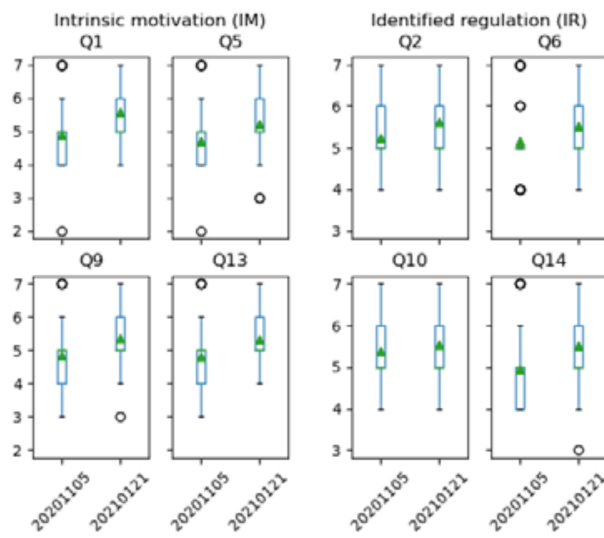

Q10 Q14

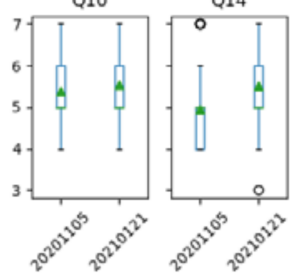

External regulation (ER)

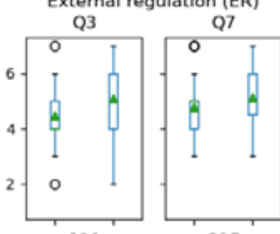

Amotivation (AM)
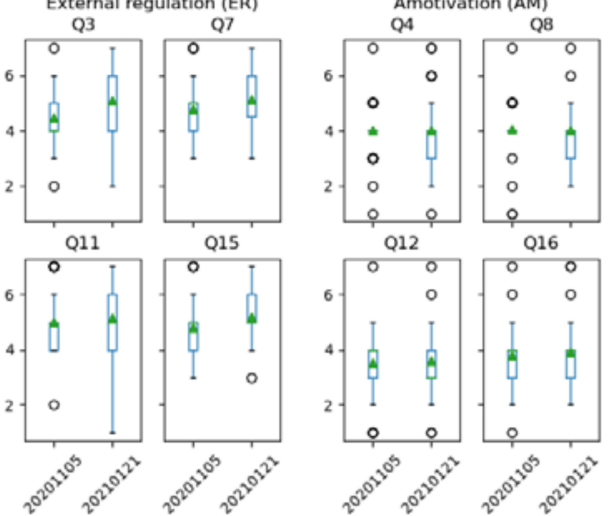

(b)

Figure 5. The results of the distributions of the SIMS scores in learning motivation changed after participating in the design thinking teaching lessons: (a) The first semester of the 2019 academic year; (b) The first semester of the 2020 academic year.

From the results of the questionnaire presented in Table 2 and SIMS, the results of the change in learning motivation showed that for external regulation (ER), some students expressed in class that they must take iOS programming in order to obtain course credits. Therefore, there is no particularly high external learning motivation at the beginning of the semester. In terms of identified regulation (IR), students agree that iOS programming skills are in strong demand in the job market, and they understand and agree with the importance of courses. In terms of intrinsic motivation (IM), some students expressed in the classroom that they love to use iPhone and therefore wanted to learn iOS programming in order to design and implement mobile APPs by themselves. In terms of amotivation (AM), students are relatively indifferent and uninterested in the methods of design thinking at the beginning. Subsequently, the results of the post-test of the SIMS exhibited from the factors above that the students have a higher degree of learning identity for the iOS course combined with design thinking.

The students play the role of designer in the course and design solutions by themselves. Through this the students can share ideas and practice design activities in the course. In the interactive teaching context, conceptual design focuses on convenience and presentation discussion, which is mainly based on sticky notes and graphic drawing discussions. In addition, when students feel that the solutions are recognized and supported by other students and teachers in the course, there is an upward trend in the curves of ER, IR, and IM. Moreover, it was observed in Figure 5 that AM for students in the first semester of the 2019 academic year was lower that relays more interest in the iOS courses incorporating with design thinking methods, and the number of indifferent and uninterested students decreased. However, the students in the first semester of the 2020 academic year were less interested in the iOS courses incorporating with design thinking methods, while the 
number of indifferent and disinterested students increased according to the results of the post-test of the SIMS. One of the possible reasons is that in the 2020 academic year, due to the impact of COVID-19, this project stopped to hire an external expert to organize the design thinking workshops for on-site collaborative teaching and experience sharing, which affected the learning motivation and interest of some students.

\subsection{Student Outcomes}

After completing this course, some of the students' final projects showed achievements that were particularly interesting. For example, two students in the first iteration utilized design thinking methods learned in this course to participate in an off-campus project competition. The design results of the proposed "AI Vegetable Recognition" APP are depicted as follows: The user can fill in the name of the ingredient or recipe in the search bar to search for a dish. If the user is not sure which kind of dish the vegetable is, or if the cabbage and Chinese cabbage are so similar that the user is unable to distinguish it, the user can use the AI image recognition function to recognize the vegetable and quickly search for the relevant cooking recipes. Figure 6 shows the development of the students AI Vegetable Recognition App that utilizes the design thinking methods learned in this course. The workflows are depicted as follows: (1) The students use Keras [29] to train the AI model. After training, the students store the model and use coremltools to convert the model to the file format of mlmodel supported by Apple Core ML framework [30]. Finally, the APP is implemented using the Swift language. As a result, the APP can take a photo from the camera and output the vegetable name after obtaining the maximum classification probability by the trained neural network model. After recognizing the name of the vegetable, the system shows the relevant cooking recipes.

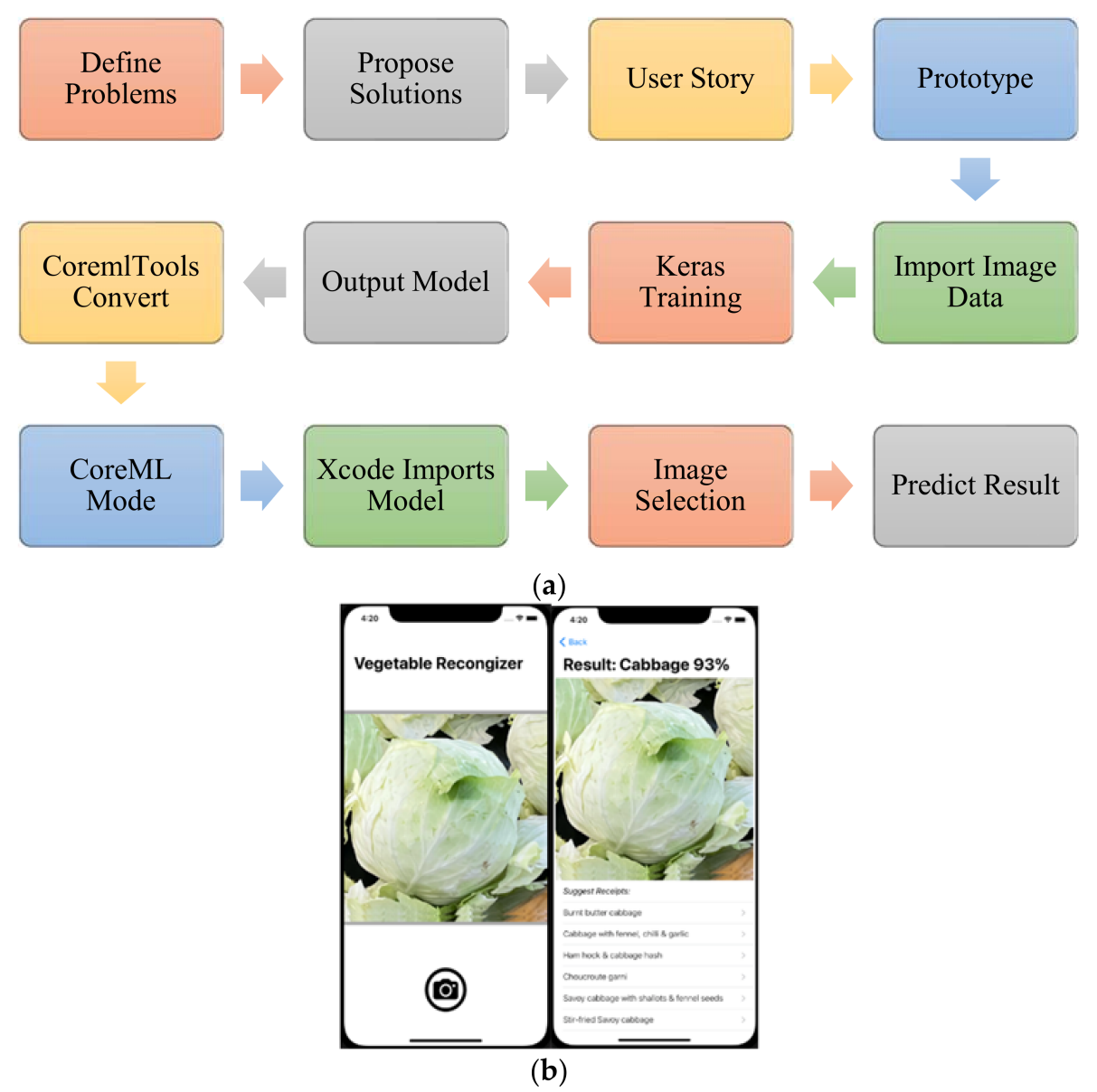

Figure 6. The development of the AI Vegetable Recognition App that utilizes the design thinking methods learned in this course: (a) The system workflow; (b) The implemented Vegetable Recognition App. 


\subsection{Student Feedback}

For the "iOS Programming" course in the first semester of the 2019 academic year, the opinions of the students in the final questionnaire are as follows:

- I think the "design thinking" introduced by the external expert is very helpful, and I like this teaching method very much, and it has benefited me a lot!

- I hope there will be opportunities to invite external experts to teach UX analysis courses in the future.

- For the "iOS Programming" course in the first semester of the 2020 academic year, the opinions of the students in the final questionnaire are as follows:

- The speed of demonstration during teaching can be a little slower.

- Let me write a great app. It's great, thank you teacher.

The feedback received from the students' responses can reveal that the teaching methods incorporating design thinking can enhance the learning motivation and help cultivate students' learning, thinking and problem-solving skills. The students appreciated and had positive feedback on the design thinking workshops. Nonetheless, in teaching, some students need more time to practice programming. Teachers should observe the progress of students and adjust the speed of teaching appropriately.

\section{Discussion and Conclusions}

In [31], Pham et al. described and reported the lessons learned from a design thinking workshop focusing on app development with industry partners at the University of Hamburg, Germany. From the educator's perspective, the internal goal of inspiring creativity was achieved, students worked autonomously and reported a strong feeling of accomplishment. The internal goal of improving students' confidence and enabling them to come up with ideas in a limited amount of time is partially achieved. The students expressed positive feedback about the working sessions which forced them to focus on the essential parts of their ideas; they appreciated and engaged with the activities. From the workshop, the students gained a human-centered perspective towards the generation of innovative solutions. The workshop had the effect of changing the students' perspective towards a human-centered approach. However, the proposed empirical study lacks quantitative analysis, although it does provide some valuable observations and suggestions [31].

In [32], Gama et al. described a CBL + DT framework that combines challenge-based learning (CBL), design thinking (DT) and Lean Startup methods to inspire students to learn how to think creatively and create solutions for real-world problems. In this research, the authors instantiated the proposed CBL + DT framework in an undergraduate semester course of mobile programming for computing students and computing novices (e.g., Design, Architecture). The authors developed a questionnaire with three questions respectively representing variables concerning the student's perceived confidence in developing iOS apps, the perceived motivation to learn given by the methodology and perceived self-motivation to learn. The quantitative results showed students agree that the CBL + DT framework helped them learn new things, with agreement of $76 \%$ and $82 \%$ from computing students and computing novices, respectively. Concerning the course motivating students to learn new things, the computing students seemed to be slightly less $(76 \%)$ motivated than the computing novice (91\% in agreement). Further, the CBL + DT framework was mentioned as a positive aspect by both groups of students. The majority of respondents mentioned the short duration of the course as a negative point: "Time seemed too short sometimes, many topics could get more classes, and learning object-oriented programming requires practice..." (Computing novice) [32]. From our student feedback in Section 4.4., some students responded that "The speed of demonstration during teaching can be a little slower." We agreed with the authors' observations in [32], some students need more time to practice programming while teaching mobile app development.

Qin et al. [33] propose a set of programming teaching methods for iOS APP mobile development with creative design to improve students' programming thinking. The authors adopt design thinking tools, e.g., user portrait, pain point analysis, finding root 
cause, mind landscape, app prototyping, to help students to generate ideas and implement iOS mobile apps. Through the proposed learning methods, the authors teach students how programming changes the way we view the world, and how to change the world through programming. The authors provide a step-by-step grammar learning MOOC and topical discussion course to help students to understand how the program works and finally training the student teams through app development competitions. The proposed empirical study lacks qualitative and quantitative analysis [33].

Our study focused on the changes in the students' learning motivations after participating in the design thinking teaching method and provides qualitative and quantitative analysis. In this study, we explored the behaviors of TVE students in a mobile application programming class and the changes in their learning motivations after participating in the design thinking program. Through the methods of designing thinking, this study successfully designed the course content and evaluation methods to let students develop solutions to practical problems, encourage students to discuss, and cultivate the students' active learning, thinking, and problem-solving abilities. After the students went through the iOS programming course that incorporated design thinking methods, positive responses were observed from the final projects and questionnaires. Subsequently, the teaching methods that utilize design thinking improve the way students think in the TVE system. Through design thinking and practice, teachers can help students to discuss and think more in solving real-world problems. The results of the post-test of the SIMS exhibition show that the students have a higher degree of learning identity for the iOS course combined with design thinking. The study results show that design thinking can stimulate students' desire to devote themselves to learning activities and improve their learning motivation.

Author Contributions: Conceptualization, T.-H.H.; Data curation, T.-H.H.; Methodology, T.-H.H. and G.-J.H.; Validation, T.-H.H., G.-J.H. and A.R.S.; Writing—original draft, T.-H.H.; Writing-review and editing, A.R.S. All authors have read and agreed to the published version of the manuscript.

Funding: This research was funded by Taiwan's Ministry of Education, grant number: PSK1080052 and PSK1090419.

Institutional Review Board Statement: Not applicable.

Informed Consent Statement: Informed consent was obtained from all subjects involved in the study.

Data Availability Statement: Not applicable.

Acknowledgments: The authors wish to express their gratitude to the Taiwan's Ministry of Education for support this research.

Conflicts of Interest: The authors declare no conflict of interest.

\section{References}

1. Ma, L.; Li, X.; Su, Z. The Problems and Solutions Existing in the Autonomous Learning under the Network Environment. In Proceedings of the 2013 the International Conference on Education Technology and Information System (ICETIS 2013), Sanya, China, 21-22 June 2013; pp. 854-857.

2. Tishman, S.; Perkins, D.N.; Jay, E. The Thinking Classroom: Learning and Teaching in a Culture of Thinking, 1st ed.; Pearson Education: Boston, MA, USA, 1994.

3. Thoring, K.; Mueller, R. Understanding design thinking: A process model based on method engineering. In Proceedings of the 13th International Conference on Engineering and Product Design Education, London, UK, 8-9 September 2011; pp. 493-498.

4. Banerjee, B.; Gibbs, T. Teaching the Innovation Methodology at the Stanford d.school. In Creating Innovation Leaders: A Global Perspective, 1st ed.; Banerjee, B., Ceri, S., Eds.; Springer International Publishing: Cham, Switzerland, 2016; pp. 163-174.

5. Tu, J.-C.; Liu, L.-X.; Wu, K.-Y. Study on the Learning Effectiveness of Stanford Design Thinking in Integrated Design Education. Sustainability 2018, 10, 2649. [CrossRef]

6. Engineering Technology Education Certification and Curriculum Committee Meeting Record; Department of Computer Science and Information Engineering, Southern Taiwan University of Science and Technology: Tainan, Taiwan, 2018; (Discussed on 2 May 2018, Unpublished Internal Document).

7. Dunne, D.; Martin, R. Design thinking and how it will change management education: An interview and discussion. Acad. Manag. Learn. Educ. 2006, 5, 512-523. [CrossRef] 
8. Glen, R.; Suciu, C.; Baughn, C. The need for design thinking in business schools. Acad. Manag. Learn. Educ. 2014, $13,653-667$. [CrossRef]

9. Brown, T.J.; Kuratko, D.F. The impact of design and innovation on the future of education. Psychol. Aesthet. Creat. Arts 2015, 9, 147-151. [CrossRef]

10. Brown, T.J.; Wyatt, J. Design thinking for social innovation. Stanf. Soc. Innov. Rev. 2010, 8, 30-35. [CrossRef]

11. Cook, K.L.; Bush, S.B. Design thinking in integrated STEAM learning: Surveying the landscape and exploring exemplars in elementary grades. Sch. Sci. Math. 2018, 118, 93-103. [CrossRef]

12. Avcu, Y.; Er, K. Design Thinking Applications in Teaching Programming to Gifted Students. J. Educ. Technol. Online Learn. 2020, 3 , 1-30. [CrossRef]

13. Tsai, M.-J.; Wang, C.-Y. Assessing Young Students' Design Thinking Disposition and Its Relationship With Computer Programming Self-Efficacy. J. Educ. Comput. Res. 2020, 59, 410-428. [CrossRef]

14. Rajashekharaiah, K.M.M.; Pawar, M.; Patil, M.S.; Kulenavar, N.; Joshi, G.H. Design Thinking Framework to Enhance Object Oriented Design and Problem Analysis Skill in Java Programming Laboratory: An Experience. In Proceedings of the 2016 IEEE 4th International Conference on MOOCs, Innovation and Technology in Education (MITE), Madurai, India, 9-10 December 2016; pp. 200-205. [CrossRef]

15. Brown, T. Design thinking. Harv. Bus. Rev. 2008, 86, 84-92. [PubMed]

16. Cross, N. Design Thinking: Understanding How Designers Think and Work, 1st ed.; Berg: Oxford, UK, 2011.

17. Dorst, K.; Cross, N. Creativity in the design process: Co-evolution of problem-solution. Des. Stud. 2001, 22, 425-437. [CrossRef]

18. Henriksen, D.; Richardson, C.; Mehta, R. Design thinking: A creative approach to educational problems of practice. Think. Ski. Creat. 2017, 26, 140-153. [CrossRef]

19. Deci, E.L.; Ryan, R.M. The general causality orientations scale: Self-determination in personality. J. Res. Personal. 1985, 19, 109-134. [CrossRef]

20. Deci, E.L. On the nature and functions of motivation theories. Psychol. Sci. 1992, 3, 167-171. [CrossRef]

21. Escher, C.; Creutzfeldt, J.; Meurling, L.; Hedman, L.; Kjellin, A.; Felländer-Tsai, L. Medical students' situational motivation to participate in simulation based team training is predicted by attitudes to patient safety. BMC Med. Educ. 2017, 17. [CrossRef] [PubMed]

22. Guay, F.; Vallerand, R.J.; Blanchard, C. On the Assessment of Situational Intrinsic and Extrinsic Motivation: The Situational Motivation Scale (SIMS). Motiv. Emot. 2000, 24, 175-213. [CrossRef]

23. Ryan, R.M.; Deci, E.L. Intrinsic and extrinsic motivations: Classic definitions and new directions. Contemp. Educ. Psychol. 2000, 25, 54-67. [CrossRef] [PubMed]

24. Gutiérrez, M.; Ruiz, L.; López, E. Perceptions of Motivational Climate and Teachers' Strategies to Sustain Discipline as Predictors of Intrinsic Motivation in Physical Education. Span. J. Psychol. 2010, 13, 597-608. [CrossRef] [PubMed]

25. Dam, R.F.; Siang, T.Y. 5 Stages in the Design Thinking Process. Available online: https:/ /www.interaction-design.org/literature/ article/5-stages-in-the-design-thinking-process (accessed on 11 February 2021).

26. Lee, M.; Tserng, H. Applying knowledge map for junior construction engineer. In Proceedings of the 23rd International Symposium on Robotics and Automation in Construction (ISARC 2006), Tokyo, Japan, 3-5 October 2006; pp. 746-750.

27. Netemeyer, R.G.; Bearden, W.O.; Sharma, S. Scaling Procedures. Issues and Applications, 1st ed.; Sage Publications: London, UK, 2003.

28. PSPP-GNU Project-Free Software Foundation-GNU.org. Available online: https://www.gnu.org/software/pspp/ (accessed on 2 February 2021).

29. Keras: Deep Learning for Humans. Available online: https:/ / github.com/fchollet/keras (accessed on 10 June 2020).

30. Core ML. Apple Developer Documentation. Available online: https://developer.apple.com/documentation/coreml (accessed on 20 July 2020).

31. Pham, Y.D.; Fucci, D.; Maalej, W. A First Implementation of a Design Thinking Workshop during a Mobile App Development Course Project. In Proceedings of the 2018 IEEE/ACM International Workshop on Software Engineering Education for Millennials (SEEM), Gothenburg, Sweden, 2 June 2018; pp. 56-63.

32. Gama, K.; Castor, F.; Alessio, P.; Neves, A.; Araujo, C.; Formiga, R.; Soares-Neto, F.; Oliveira, H. Combining Challenge-Based Learning and Design Thinking to Teach Mobile App Development. In Proceedings of the 2018 IEEE Frontiers in Education Conference (FIE), San Jose, CA, USA, 3-6 October 2018; pp. 1-5.

33. Qin, L.; Li, B.; Yang, L.-P. Programming Thinking Training and Course Design for iOS Mobile Development. In Proceedings of the 15th International Conference on Computer Science \& Education (ICCSE), Delft, The Netherlands, 18-22 August 2020; pp. 577-582. 